\title{
Epidural anesthesia for pilonidal sinus surgery: ropivacaine versus levobupivacaine
}

\author{
Zeynep Nur Orhon, Emine Nursen Koltka, Sibel Devrim, Sevil Tüfekçi, \\ Serkan Doğru, and Melek Çelik \\ Department of Anesthesiology and Reanimation, Göztepe Training and Research Hospital, Istanbul Medeniyet \\ University, Istanbul, Turkey
}

\begin{abstract}
Background: Epidural anesthesia is one of the best options for lower abdominal and lower limb surgery. However, there have been insufficient reports regarding the use of epidural anesthesia for pilonidal sinus surgery. The present study was performed to compare the clinical profiles of epidural block performed with $0.75 \%$ levobupivacaine and $0.75 \%$ ropivacaine in this procedure.

Methods: Thirty patients undergoing pilonidal sinus surgery were randomly allocated into two groups: one group received levobupivacaine and the other received ropivacaine at $0.75 \%$ in a volume of $10 \mathrm{ml}$. Arterial blood pressure, heart rate, oxygen saturation, the onset time of analgesia and duration of block, highest sensory block level, perioperative and postoperative side effects, and patients' and surgeons' satisfaction were recorded.

Results: Hemodynamic stability was maintained in both groups throughout surgery. The onset time of analgesia (the time from epidural injection of local anesthetic to reach $\mathrm{L}_{2}$ sensorial block) was $6.26 \pm 3.49 \mathrm{~min}$ in the levobupivacaine group and $4.06 \pm 1.75 \mathrm{~min}$ in the ropivacaine group $(\mathrm{P}=0.116)$. The duration of sensorial block (time for regression of sensory block to $\left.\mathrm{L}_{2}\right)$ was $297.73 \pm 70.94 \mathrm{~min}$ in group $\mathrm{L}$ and $332.40 \pm 102.22 \mathrm{~min}$ in group $\mathrm{R}(\mathrm{P}=0.110)$. Motor block was not seen in any of the patients in the study groups. Patients' and surgeons' satisfaction with the anesthetic technique were mostly excellent in both groups.

Conclusions: In patients undergoing pilonidal sinus surgery, both levobupivacaine and ropivacaine produce rapid and excellent epidural block without leading to motor block or significant side effects. Although not statistically significant, the onset time of anesthesia was shorter and the duration of effect was longer with ropivacaine than with levobupivacaine in this study.
\end{abstract}

Key Words: Epidural anesthesia, Levobupivacaine, Pilonidal sinus surgery, Ropivacaine.

Corresponding author: Zeynep Nur Orhon, M.D.

Department of Anesthesiology and Reanimation, Göztepe Training and Research Hospital, Istanbul Medeniyet University, Hızırbey Cad. Cüre Apt. 221/4, Göztepe/Istanbul, 34730, Turkey

Tel: 902165665740 , Fax: 902165709081

E-mail: zeynepnurorhon@gmail.com

Received: April 4, 2014.

Revised: 1st, June 20, 2014; 2nd, August 12, 2014; 3rd, August 15, 2014. Accepted: August 15, 2014.

Korean J Anesthesiol 2015 April 68(2): 141-147

http://dx.doi.org/10.4097/kjae.2015.68.2.141

\section{Introduction}

Anorectal surgical procedures are among the most common surgical operations; more than $90 \%$ of these procedures are performed on an ambulatory basis [1,2]. This surgery is performed frequently in adolescents and adults in Turkey. Local infiltration anesthesia, spinal anesthesia, and general anesthesia are commonly used anesthetic techniques for anorectal surgery [3-5].

However, there are a number of difficulties with these anesthesia techniques. Local infiltration anesthesia is frequently in-

(c) This is an open-access article distributed under the terms of the Creative Commons Attribution Non-Commercial License (http://creativecommons.org/ licenses/by-nc/3.0/), which permits unrestricted non-commercial use, distribution, and reproduction in any medium, provided the original work is properly cited. 
adequate to provide painless surgery and is not comfortable for the patient. In this situation, the surgeon does not work under the best conditions and may be unable to complete the surgery easily and successfully. Therefore, the dose of local anesthetic has to be increased, which may lead to toxicity [6,7].

General anesthesia is used frequently. However, putting overweight patients into the prone position is especially difficult. Moreover, patients undergoing general anesthesia may experience complications due to this position leading to vertebral and limb injuries [8]. In addition, muscle relaxants must be given when general anesthesia is applied for endotracheal intubation. Postoperative nausea and vomiting are also problems after general anesthesia. These issues lead to an increased economic cost and delayed discharge from hospital $[9,10]$.

Due to its more rapid onset, spinal anesthesia is commonly used for this procedure; however, spinal anesthesia is not safe for all patients (e.g., those with ischemic heart disease, and renal or hepatic diseases in which hypotension is harmful). Spinal anesthesia may be associated with significant side effects, such as hypotension, bradycardia, shivering, nausea, vomiting, significant headache, backache, and urinary retention [11]. The side effects of epidural anesthesia are similar to those of spinal anesthesia, but are less common and less serious [12]. However, few studies have addressed the use of epidural anesthesia for this procedure.

Levobupivacaine and ropivacaine are new long-acting local anesthetics that were developed following reports of bupivacaine-related severe toxicity. Both of these agents are pure left isomers, and based on their three-dimensional structure they have less toxicity to both the central nervous system and the heart. The clinical profiles of levobupivacaine and ropivacaine are similar to that of racemic bupivacaine, and the minimal differences among the three agents are mainly related to the slightly different anesthetic potency. They produce effects similar to other local anesthetics via reversible inhibition of sodium ion influx in nerve fibers [13-15]. We prefer to use both of these drugs because of their similarity.

The primary aim of this study was to compare the onset time of ropivacaine and levobupivacaine and to evaluate their other effects. The secondary aim was to assess the efficiency of epidural anesthesia in pilonidal sinus surgery.

\section{Materials and Methods}

Institutional approval from Medeniyet University Goztepe Training and Research Hospital and patient's written informed consent to participate in this study were obtained. Patients with neurological or neuromuscular disease, bleeding disorders, infection at the injection site, clinically significant cardiovascular, respiratory, renal, hepatic, or metabolic disease, history of allergic reactions to any local anesthetic drug and patients who refused epidural anesthesia were excluded from the study. A total of 30 patients who were scheduled for pilonidal sinus surgery and American Society of Anesthesiologists (ASA) physical status I-II between 18 and 51 years of age was enrolled in this prospective, randomized study.

Patients were randomly assigned to receive one of the two local anesthetic drugs for epidural anesthesia. Patients were randomized using computer-generated random numbers, and information regarding the randomization was stored in sealed, consecutively numbered envelopes.

Routine preoperative evaluation of each patient was performed the day before surgery. The method of anesthesia was explained to the patients and questions about the procedure were answered. No premedication was given to the patients. In the operating room, an 18-G intravenous cannula was inserted and $15 \mathrm{ml} / \mathrm{kg}$ balanced crystalloid solution was administered to all patients. Standard monitoring was used throughout the study, including electrocardiography, non-invasive blood pressure, heart rate, and pulse oximetry (KMA 275; Petas, Ankara, Turkey).

All patients received epidural anesthesia using a standard midline approach in the sitting position. The insertion area was prepared using antiseptic solution and then $2 \mathrm{ml}$ of $2 \%$ lidocaine were applied into the skin and subcutaneous tissue to induce local anesthesia. Then, 3-4 $\mathrm{ml}$ of $0.9 \% \mathrm{NaCl}$ solution was injected through an 18-G Tuohy needle to find the epidural space at the $\mathrm{L}_{3}-\mathrm{L}_{4}$ or $\mathrm{L}_{4}-\mathrm{L}_{5}$ interspaces using the loss of resistance technique. Patients in group L received $10 \mathrm{ml}$ of $0.75 \%$ levobupivacaine (Chirocaine $^{\circledR}$, Abbott Laboratories, Chicago, IL, USA) and those in group $\mathrm{R}$ received $10 \mathrm{ml}$ of $0.75 \%$ ropivacaine (Naropin ${ }^{\circledR}$, Astra Zeneca, Wilmington, DE, USA) for epidural anesthesia. After negative aspiration of blood, $3 \mathrm{ml}$ of the study drug were injected as a test dose. Approximately 3-5 min later, the remaining dose was administered. An epidural catheter was not applied. After completion of epidural injection, patients were placed in the supine position. Mean arterial pressure (MAP), heart rate (HR), hemoglobin $\mathrm{O}_{2}$ saturation values $\left(\mathrm{SpO}_{2}\right)$ were recorded every $5 \mathrm{~min}$ throughout surgery. An observer blinded to the group assignments recorded the evolution of sensory block (using the pinprick sensation test) and motor block by modified Bromage scale ( 0 . No impairment; 1 , unable to raise extended legs but able to move knees and ankles; 2 , unable to raise extended legs as well as unable to flex knees, able to move feet; 3, unable to flex ankle, feet, or knees) [16]. The onset time of analgesia (the time from epidural injection of local anesthetic to reaching $\mathrm{L}_{2}$ sensorial block), and levels of sensorial and motor block were recorded every $2 \mathrm{~min}$. Maximum sensorial and motor block levels were also recorded. Patients were then moved into the prone position.

It was planned to treat bradycardia $(\mathrm{HR}<50$ beats/min $)$ with 
atropine $(0.01 \mathrm{mg} / \mathrm{kg})$, and hypotension (decrease in systolic arterial blood pressure 30\% lower than baseline) with intravenous boluses of crystalloid solution or ephedrine (5-10 mg).

Patients were not sedated during surgery. It was planned to administer $1 \mu \mathrm{g} / \mathrm{kg}$ fentanyl as a supplementary analgesic if required. Perioperative and postoperative side effects, such as hypotension, bradycardia, shivering, nausea, vomiting, headache, backache, and urinary retention, were assessed for $2 \mathrm{~h}$. A threepoint scoring system was used to evaluate patients' and surgeons' satisfaction with the anesthetic technique, in which 1 is poor, 2 is good, and 3 is excellent, as graded by a blinded investigator in the operating theater immediately after the operation or in the postoperative care unit.

Sample size estimation ( $\alpha=0.05$ and $\beta=0.1$ ) indicated that 22 patients per group were needed to detect a 2-min reduction in the onset time of analgesia, equivalent to one standard deviation (SD) from pilot data. The data obtained were analyzed using SPSS version 20.0 for Windows (SPSS, IL, Chicago, USA).

Table 1. Patients' Characteristics and Duration of Surgery in the Two Groups

\begin{tabular}{lccc}
\hline & $\begin{array}{c}\text { Group R } \\
\mathrm{n}=15\end{array}$ & $\begin{array}{c}\text { Group L } \\
\mathrm{n}=15\end{array}$ & \multirow{2}{*}{$\mathrm{P}$} \\
\cline { 2 - 3 } & mean $\pm \mathrm{SD}$ & mean \pm SD & \\
\hline Age & $28.66 \pm 7.56$ & $26.93 \pm 10.34$ & 0.328 \\
Height & $173.20 \pm 5.79$ & $175.80 \pm 9.71$ & 0.204 \\
Weight & $76.73 \pm 9.47$ & $79.93 \pm 16.28$ & 0.787 \\
Duration of surgery & $47.86 \pm 16.12$ & $46.26 \pm 14.01$ & 0.786 \\
Male & $13(86.7 \%)$ & $15(100 \%)$ & 0.483 \\
Female & $2(13.3 \%)$ & 0 & \\
\hline
\end{tabular}

Data are presented as means \pm SD. There was no significant difference between the groups. R: Ropivacaine, L: Levobupivacaine.

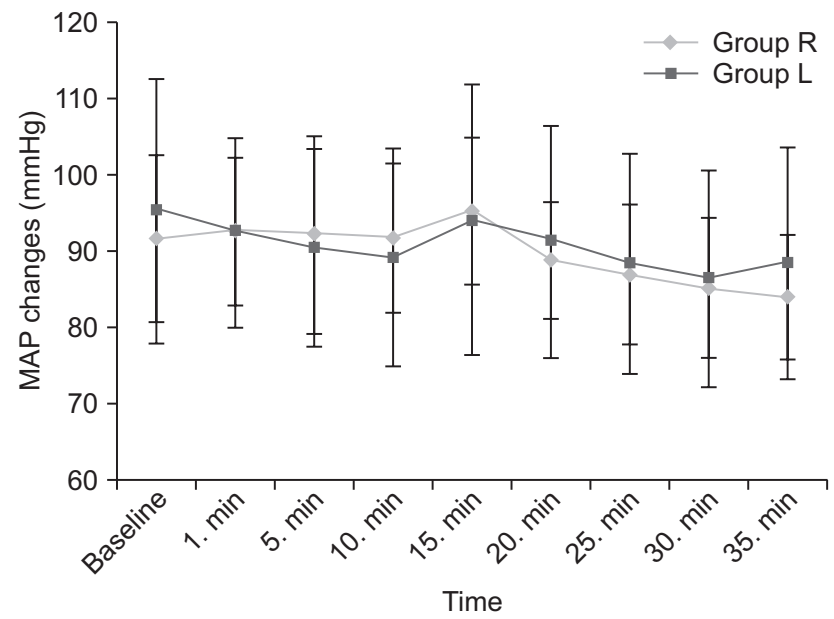

Fig. 1. Mean arterial pressure (MAP) changes during surgery in the two groups. R: Ropivacaine, L: Levobupivacaine.
Demographic data were analyzed using Student's $t$ test. Twoway ANOVA for repeated measures was used to analyze changes over time. Ordinal data were analyzed using the Mann-Whitney $\mathrm{U}$ test and the $\chi^{2}$ test with the appropriate corrections. In all analyses, $\mathrm{P}<0.05$ was taken to indicate statistical significance. Continuous variables are presented as means $( \pm \mathrm{SD})$ or medians (range).

\section{Results}

No difference in patient characteristics or duration of surgery was observed between the two groups (Table 1). Hemodynamic stability was maintained in both groups throughout the surgery. Neither mean arterial pressure measurements nor heart rate levels showed significant differences between the groups (Figs. 1 and 2). There were statistically significant differences in $\mathrm{SpO}_{2}$ levels between the groups at 15 and $35 \mathrm{~min}$. However, these differences were clinically insignificant (Table 2).

The onset time of analgesia was $6.26 \pm 3.49 \mathrm{~min}$ in group $\mathrm{L}$ and $4.06 \pm 1.75 \mathrm{~min}$ in group $\mathrm{R}(\mathrm{P}=0.116)$ (Table 3$)$. The duration of sensorial block was $297.73 \pm 70.94 \mathrm{~min}$ in group L and $332.40 \pm 102.22 \mathrm{~min}$ in group $\mathrm{R}(\mathrm{P}=0.110)$ (Table 3$)$. Motor block was not seen in any of the patients in the study groups. Supplementary analgesic was required in only one patient in the ropivacaine group (6.6\%). None of the patients required general anesthesia to complete the surgery. Mean sensorial block level was $\mathrm{T}_{7}$ (max. $\mathrm{T}_{2}$ in 2 patients) in group $\mathrm{L}$ and $\mathrm{T}_{8}\left(\max . \mathrm{T}_{6}\right.$ in 1 patient) in group R. The duration of sensorial block was 297.73 $\pm 70.94 \mathrm{~min}$ ( $\max .438 \mathrm{~min}$, $\mathrm{min} .165 \mathrm{~min}$ ) in group L and $332.40 \pm 102.22 \mathrm{~min}(\max .570 \mathrm{~min}$, $\mathrm{min} .98 \mathrm{~min}$ ) in group R. Significant hypotension was observed in only one patient (whose maximum sensorial block level was $\mathrm{T}_{2}$ ) in group $\mathrm{L}$ at $40 \mathrm{~min}$ af-

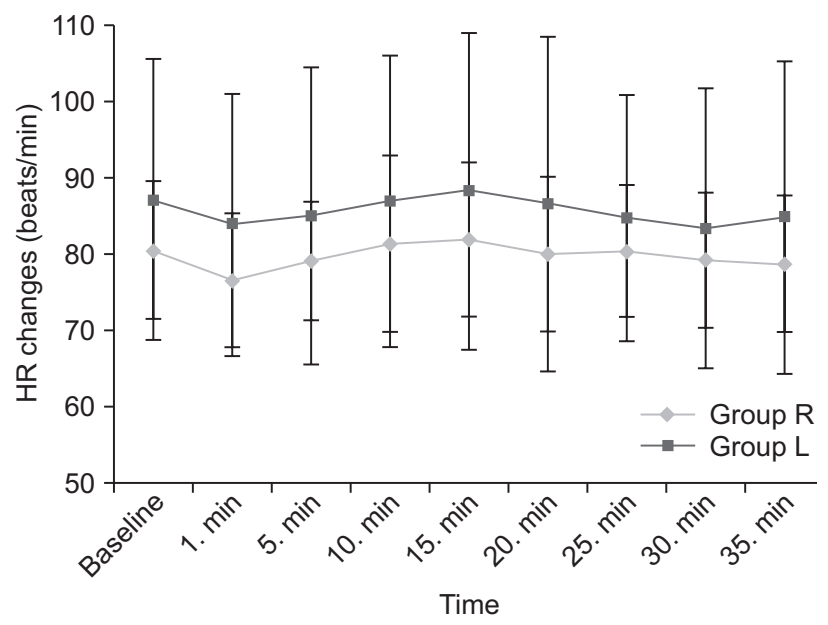

Fig. 2. Heart rate measurements during surgery in the two groups. R: Ropivacaine, L: Levobupivacaine. 
Table 2. $\mathrm{SpO}_{2}$ Measurements at Various Time Points from Pre-anesthesia to 35 min after Epidural Injection

\begin{tabular}{lccl}
\hline & $\begin{array}{c}\text { Group R } \\
\mathrm{n}=15\end{array}$ & $\begin{array}{c}\text { Group L } \\
\mathrm{n}=15\end{array}$ & \multirow{2}{*}{$\mathrm{P}$} \\
\cline { 2 - 3 } & mean $\pm \mathrm{SD}$ & mean $\pm \mathrm{SD}$ & \\
\hline $\mathrm{SpO}_{2}$ Baseline & $98.00 \pm 0.75$ & $98.13 \pm 0.91$ & 0.520 \\
$\mathrm{SpO}_{2} 1 \mathrm{~min}$ & $98.00 \pm 0.84$ & $98.26 \pm 1.09$ & 0.200 \\
$\mathrm{SpO}_{2} 5 \mathrm{~min}$ & $98.13 \pm 0.74$ & $98.13 \pm 0.91$ & 0.840 \\
$\mathrm{SpO}_{2} 10 \mathrm{~min}$ & $98.73 \pm 0.88$ & $97.93 \pm 1.48$ & 0.082 \\
$\mathrm{SpO}_{2} 15 \mathrm{~min}$ & $99.06 \pm 0.70$ & $98.26 \pm 1.03$ & $0.026^{*}$ \\
$\mathrm{SpO}_{2} 20$ min & $98.93 \pm 0.79$ & $98.86 \pm 1.24$ & 0.825 \\
$\mathrm{SpO}_{2} 25 \mathrm{~min}$ & $98.73 \pm 1.03$ & $99.13 \pm 1.12$ & 0.173 \\
$\mathrm{SpO}_{2} 30$ min & $98.73 \pm 0.96$ & $99.00 \pm 1.41$ & 0.203 \\
$\mathrm{SpO}_{2} 35$ min & $98.53 \pm 0.99$ & $99.26 \pm 1.09$ & $0.014 *$ \\
\hline
\end{tabular}

Data values are presented as means $\pm \mathrm{SD}$. *Statistically significant difference between the groups $(\mathrm{P}<0.05$, Mann-Whitney U-test). R: Ropivacaine, L: Levobupivacaine.

ter epidural injection; it was treated successfully by intravenous infusions of crystalloid solution and ephedrine $10 \mathrm{mg}$.

Patients' satisfaction with the anesthetic technique was excellent in 12 patients and good in 3 patients in group L, and excellent in 10 patients and good in 5 patients in group R. All except one patient in each group reported that they would accept the same anesthetic procedure for future operations. Surgeons' satisfaction with the anesthetic technique was excellent for 14 and good for 1 surgeon in each group. Side effects, such as bradycardia, hypotension, shivering, nausea and vomiting, headache, backache, urinary retention, and neurological complications, were not seen in any patient in either group.

\section{Discussion}

This study was designed to compare two local anesthetics with respect to hemodynamic stability, onset of action, level and duration of block, perioperative and postoperative side effects, and patients' and surgeons' satisfaction, and to evaluate the efficiency of epidural anesthesia, which has fewer side effects than spinal anesthesia in pilonidal sinus surgery. In the present study, hemodynamic stability was maintained in both groups throughout the surgery. Although not statistically significant, the onset time of analgesia was shorter in group $\mathrm{R}$ than group L, and the duration of sensorial block was longer in group $\mathrm{R}$ than group $\mathrm{L}$. Motor block was not seen in any of the patients. Supplementary analgesic was required in only one patient in the ropivacaine group.

There is only one previous report in the published literature regarding patients undergoing pilonidal sinus surgery with epidural anesthesia. Pala et al. [17] compared conventional epidural anesthesia with segmental epidural anesthesia, which was achieved with small doses of local anesthetics, in pilonidal
Table 3. Onset Time of Analgesia and Duration of Sensorial Block

\begin{tabular}{lcccc}
\hline & $\begin{array}{c}\text { Group R } \\
\mathrm{n}=15\end{array}$ & $\begin{array}{c}\text { Group L } \\
\mathrm{n}=15\end{array}$ & $\mathrm{P}$ \\
\cline { 2 - 3 } & mean \pm SD & mean \pm SD & \\
\hline Onset time of analgesia (min) & $4.06 \pm 1.75$ & $6.26 \pm 3.49$ & 0.116 \\
Duration of sensorial block (min) & $332.40 \pm 102.22$ & $297.73 \pm 70.94$ & 0.110 \\
\hline
\end{tabular}

Data are presented as means \pm SD. There was no statistically significant difference between the groups ( $\mathrm{P}>0.05$, Mann-Whitney U-test). R: Ropivacaine, L: Levobupivacaine.

sinus surgery. Patients were divided into two groups: Group I, conventional epidural anesthesia with $75 \mathrm{mg}$ bupivacaine (0.5\%); Group II, low-dose epidural anesthesia with $30 \mathrm{mg}$ bupivacaine (0.5\%). Sensory block onset time was shorter in Group I, sensory block offset time, time of discharge from the post-anesthetic care unit, time to the first urination and analgesic requirement were shorter in Group II. Maximum sensory and motor block levels were lower in Group II. The authors concluded that in pilonidal sinus surgery low-dose epidural anesthesia induces adequate sensorial block, and because motor block did not develop, discharge criteria were achieved in the early postoperative period. Various doses of bupivacaine $(0.5 \%)$ for epidural anesthesia in this procedure were compared and found to yield adequate sensorial block. However, we compared the same dose of two local anesthetic drugs for epidural anesthesia. Our findings suggested that epidural anesthesia is a suitable technique for pilonidal sinus surgery, and the two drugs had almost identical anesthetic effects.

In a previous prospective, randomized, observer-blinded study, Peduto et al. [18] compared the onset time and duration of epidural anesthesia produced by levobupivacaine and ropivacaine. Adult ASA I-III patients undergoing elective lower limb procedures were randomized to receive epidural application of $15 \mathrm{ml}$ of $0.5 \%$ levobupivacaine $(\mathrm{n}=30$ ) or $15 \mathrm{ml}$ of $0.75 \%$ ropivacaine $(\mathrm{n}=35)$. An observer blinded to the groups evaluated the onset time and regression of motor and sensory block, and intraoperative need for fentanyl supplementation $(0.1 \mathrm{mg}$ intravenously). Onset time was $29 \pm 24$ min with levobupivacaine and $25 \pm 22 \mathrm{~min}$ with ropivacaine. Complete resolution of motor block required $105 \pm 63$ min with levobupivacaine and $95 \pm 48$ min with ropivacaine. The time for regression of sensory block to $\mathrm{T}_{12}$ was $185 \pm 77 \mathrm{~min}$ with levobupivacaine and $201 \pm 75 \mathrm{~min}$ with ropivacaine. Analgesic supplementation was required in one patient (3.5\%) receiving levobupivacaine and in two patients (5.7\%) receiving ropivacaine. They concluded that $15 \mathrm{ml}$ of $0.5 \%$ levobupivacaine produces an epidural block with the same clinical profile as $15 \mathrm{ml}$ of $0.75 \%$ ropivacaine. Although the primary surgical diagnosis and the dosage differed from those of our study, their results were in accordance with those of the present 
study with regard to the onset time of analgesia, duration of sensorial block, and supplementary analgesic requirement. However, motor block was obtained with the dose and volume used in the study by Peduto et al. [18]. This was not the desired effect in our study population and no motor block was detected in any of our patients.

Casati et al. [19] compared the onset time and duration of epidural anesthesia, and the quality of postoperative analgesia produced by levobupivacaine, racemic bupivacaine, and ropivacaine in a prospective, randomized, double-blinded study. Forty-five ASA physical status I, II, and III patients undergoing elective total hip replacement received epidural block with $0.5 \%$ levobupivacaine $(\mathrm{n}=15), 0.5 \%$ bupivacaine $(\mathrm{n}=15)$, or $0.5 \%$ ropivacaine $(\mathrm{n}=15)$. After a median volume of $15(10-18) \mathrm{ml}$ in the levobupivacaine group, $14(10-18) \mathrm{ml}$ in the bupivacaine group, and 15 (10-18) $\mathrm{ml}$ in the ropivacaine group, the onset time of sensory block was $31 \pm 16$ min with levobupivacaine, 25 \pm 19 min with bupivacaine, and $30 \pm 24$ min with ropivacaine. Six patients in the ropivacaine group (40\%) showed an intraoperative Bromage score $<2$ compared with only three patients in the levobupivacaine group (20\%), and no patients in the bupivacaine group. Recovery of pinprick sensation occurred after 214 $\pm 61 \mathrm{~min}$ with levobupivacaine, $213 \pm 53 \mathrm{~min}$ with bupivacaine, and $233 \pm 34 \mathrm{~min}$ with ropivacaine. The degree of pain relief was similar in the three groups in local anesthetic consumption and need for rescue analgesia. Motor blockade resolved progressively with no difference among the three groups. The authors concluded that $0.5 \%$ levobupivacaine produces epidural block of similar onset, quality, and duration as the same volume of $0.5 \%$ bupivacaine and $0.5 \%$ ropivacaine. The onset time and duration of epidural anesthesia were similar to those in our study. However, the quality of postoperative analgesia was not recorded in our study. Their results were comparable with our findings, with the exception of motor block.

Koch et al. [20] performed a single-blind phase IIIb study in 88 patients undergoing hip surgery. Twelve German academic hospitals were randomly assigned to three treatment groups to evaluate the efficacy of $0.5 \%$ levobupivacaine versus $0.5 \%$ bupivacaine and $0.75 \%$ ropivacaine administered as epidural anesthesia and $0.125 \%$ levobupivacaine versus $0.125 \%$ bupivacaine and $0.2 \%$ ropivacaine for postoperative analgesia. The study was designed to test the equivalence of the overall profile of levobupivacaine against bupivacaine and ropivacaine. In addition, several clinical safety parameters were assessed. With respect to the onset and offset times of sensory and motor blockade, $0.5 \%$ levobupivacaine, $0.5 \%$ bupivacaine, and $0.75 \%$ ropivacaine showed clinically significant and equivalent profiles for all primary study endpoints. However, the levobupivacaine group showed a higher demand for intraoperative analgesia. The frequency of postoperative analgesia request and pain scale scores did not differ significantly between groups, but the total drug volume required was lower in the bupivacaine group. No relevant differences between the trial groups concerning safety parameters were observed. The authors concluded that the efficacies of epidural levobupivacaine for hip surgery and postoperative analgesia were equivalent, and these drugs showed a clinical profile comparable to that of bupivacaine and a 50-60\% higher concentration of ropivacaine.

The patients in the levobupivacaine group showed a higher demand for intraoperative analgesia, in contrast to our results. Supplementary analgesic was required in only one patient in the ropivacaine group in our study, possibly because of the use of a $50 \%$ higher concentration of ropivacaine in their study [20].

In another study, McGlade et al. [21] compared the epidural use of $20 \mathrm{ml}$ of $0.5 \%$ ropivacaine and $0.5 \%$ bupivacaine in patients undergoing lower limb orthopedic surgery in a doubleblinded, randomized, multicenter study involving 67 patients. There was no significant difference between the two groups in any parameter. With the exception of the incidence of complete motor block, their results were in accordance with those of the present study in terms of the onset time of analgesia, duration of sensorial block, and supplementary analgesic requirement. The volume used by McGlade et al. resulted in motor block, which was the desired effect.

Yang et al. [22] compared the clinical efficacy and safety of epidural anesthesia produced by $20 \mathrm{ml}$ of $0.5 \%$ levobupivacaine and $20 \mathrm{ml}$ of $0.5 \%$ ropivacaine for cesarean section. Using this volume, motor block occurred in all patients in the levobupivacaine group and in 27 of 31 patients in the ropivacaine group. Motor block was the desired effect for this procedure for which a volume of approximately $20 \mathrm{ml}$ was found to be sufficient. Motor block was not necessary in the present study, and so we used a lower volume of analgesic drug. There was no difference in the onset time, segmental spread of sensory block, or analgesic supplement requirement between the two groups. However, levobupivacaine produced a longer duration of sensory block than ropivacaine (levobupivacaine $224.1 \pm 66.6 \mathrm{~min}$, ropivacaine $176.5 \pm 32.8 \mathrm{~min}, \mathrm{P}<0.05)$. This result was not in accordance with our findings. Although not statistically significant, the duration of sensorial block of ropivacaine was longer than that of levobupivacaine in the present study.

Kountoudi et al. compared $0.5 \%$ solutions of levobupivacaine and ropivacaine with regard to alterations in blood pressure and heart rate during surgery. Thirty ASA I-III patients scheduled for elective inguinal hernia repair and undergoing epidural anesthesia were randomized into two groups: group L received $0.5 \%$ levobupivacaine, while group $\mathrm{R}$ received $0.5 \%$ ropivacaine. The volume of local anesthetic given was estimated according to the patient's age and height to provide anesthesia up to the $\mathrm{T} 7 \mathrm{der}$ matome. There were no significant differences between the two 
groups in the measured parameters (HR, height of the sensory block and duration of surgery). However, MAP was significantly lower $(\mathrm{P}<0.05)$ in group $\mathrm{L}$ compared to group $\mathrm{R}$ at 15 min after epidural block. In the present study, MAP levels were stable in both groups at all measurement points.

Salvi et al. evaluated the analgesic and hemodynamic effects of ropivacaine vs. levobupivacaine in thoracic epidural for coronary artery surgery. Patients scheduled for CABG were randomized to receive ropivacaine $(\mathrm{R})$ or levobupivacaine $(\mathrm{L})$ as a $0.5 \%$ bolus $(0.1 \mathrm{ml} / \mathrm{kg})$ followed by $0.2 \%$ infusion during surgery via an epidural catheter inserted at the $\mathrm{T}_{1}-\mathrm{T}_{2}$ or $\mathrm{T}_{2}-\mathrm{T}_{3}$ interspace; sufentanil at $2.5 \mu \mathrm{g} / \mathrm{ml}$ and $1 \mu \mathrm{g} / \mathrm{ml}$ were added to the bolus and infusion solution, respectively. The onset time to achieve $T_{1}-T_{6}$ block was recorded. General anesthesia was then induced. No important differences were seen between the groups; therefore, in this setting $0.5 \% \mathrm{R}$ and $\mathrm{L}$ were equianalgesic, providing excellent analgesia and sympathetic blockade. The authors concluded that the anesthetic and hemodynamic effects of these agents are similar in this clinical setting. Salvis' results were consistent with our findings; moreover, the anesthetic and hemodynamic effects were also similar to those of the present study.

The results of the present study were similar to those of previous works with regard to hemodynamic stability, onset time of analgesia, and duration of sensorial block [18-20,23,24]. The development of motor block was reported by three studies $[18,19,21]$; however, it was not seen in any patient in our study, likely due to our use of lower drug volumes and concentrations.

In another study, Taspinar et al. [23] compared equipotent doses of ropivacaine and levobupivacaine regarding discharge criteria and the characteristics of spinal anesthesia in inguinal herniorrhaphy surgery. Combined spinal-epidural anesthesia was performed. Patients were allocated to receive $5 \mathrm{mg}$ of $0.5 \%$ ropivacaine or $3.75 \mathrm{mg}$ of $0.75 \%$ levobupivacaine, together with $25 \mu \mathrm{g}$ of fentanyl. The sensory block onset time and time to reach the $\mathrm{T}_{6}$ dermatome were significantly shorter in group LF, while the time to two-segment regression and time to first analgesic requirement were significantly shorter in group RF. All patients in group LF were Bromage 0. The time to discharge was shorter in group LF, but this difference was not statistically significant. The authors suggested that both local anesthetics could be used in walking spinal technique, that is the patients could stand up and walk right after the operation.

As in other studies, both drugs were shown to be hemodynamically safe with almost identical clinical efficacy. Epidural anesthesia using these two drugs is recommended in patients scheduled for pilonidal sinus surgery because of their advantages, such as the ability to place the patient into the prone position, hemodynamic stability, patients' and surgeons' satisfaction, early mobilization, and lack of side effects.

In conclusion, our findings showed that epidural anesthesia with either levobupivacaine or ropivacaine is a suitable anesthetic technique for pilonidal sinus surgery with respect to hemodynamic stability, onset time of analgesia, duration of sensorial block, lack of motor block and side effects, and surgeon's and patient's satisfaction.

\section{References}

1. Smith LE. Ambulatory surgery for anorectal diseases: an update. South Med J 1986; 79: 163-6.

2. Hunt L, Luck AJ, Rudkin G, Hewett PJ. Day-case haemorrhoidectomy. Br J Surg 1999; 86: 255-8.

3. Thompson-Fawcett MW, Cook TA, Baigrie RJ, Mortensen NJ. What patients think of day-surgery proctology. Br J Surg 1998; $85: 1388$.

4. Fleischer M, Marini CP, Statman R, Capella J, Shevde K. Local anesthesia is superior to spinal anesthesia for anorectal surgical procedures. Am Surg 1994; 60: 812-5.

5. Li S, Coloma M, White PF, Watcha MF, Chiu JW, Li H, et al. Comparison of the costs and recovery profiles of three anesthetic techniques for ambulatory anorectal surgery. Anesthesiology 2000; 93: 1225-30.

6. Neal JM, Bernards CM, Butterworth JF 4th, Di Gregorio G, Drasner K, Hejtmanek MR, et al. ASRA practice advisory on local anesthetic systemic toxicity. Reg Anesth Pain Med 2010; 35: 152-61.

7. Cox B, Durieux ME, Marcus MA. Toxicity of local anaesthetics. Best Pract Res Clin Anaesthesiol 2003; 17: 111-36.

8. Bund M, Heine J, Jaeger K. Complications due to patient positioning: anaesthesiological considerations. Anasthesiol Intensivmed Notfallmed Schmerzther 2005; 40: 329-39.

9. Gan TJ, Meyer T, Apfel CC, Chung F, Davis PJ, Eubanks S, et al. Consensus guidelines for managing postoperative nausea and vomiting. Anesth Analg 2003; 97: 62-71.

10. Smith HS, Smith EJ, Smith BR. Postoperative nausea and vomiting. Ann Palliat Med 2012; 1: 94-102.

11. Tarkkila P. Complications of Regional Anesthesia. 2nd ed. New York, Springer Science+Business Media, LLC. 2007, pp 149-66.

12. Twomey C, Tsui BC. Complications of Regional Anesthesia. 2nd ed. New York, Springer Science+Business Media, LLC. 2007 , pp 167-92.

13. Casati A, Putzu M. Bupivacaine, levobupivacaine and ropivacaine: are they clinically different? Best Pract Res Clin Anaesthesiol 2005; 19: $247-68$.

14. Kuthiala G, Chaudhary G. Ropivacaine: A review of its pharmacology and clinical use. Indian J Anaesth 2011; 55: 104-10. 
15. Bajwa SJ, Kaur J. Clinical profile of levobupivacaine in regional anesthesia: A systematic review. J Anaesthesiol Clin Pharmacol 2013; 29: 530-9.

16. Bromage PR. A comparison of the hydrochloride and carbon dioxide salts of lidocaine and prilocaine in epidural analgesia. Acta Anaesthesiol Scand Suppl 1965; 16: 55-69.

17. Pala Y, Okur S, Taşpınar V, Örnek D, Dönmez F, Barçın S, et al. Pilonidal sinus cerrahisinde selektif segmental epidural anestezi uygulaması. Türk Anest Rean Der Dergisi 2010; 38: 190-200.

18. Peduto VA, Baroncini S, Montanini S, Proietti R, Rosignoli L, Tufano R, et al. A prospective, randomized, double-blind comparison of epidural levobupivacaine $0.5 \%$ with epidural ropivacaine $0.75 \%$ for lower limb procedures. Eur J Anaesthesiol 2003; 20: 979-83.

19. Casati A, Santorsola R, Aldegheri G, Ravasi F, Fanelli G, Berti M, et al. Intraoperative epidural anesthesia and postoperative analgesia with levobupivacaine for major orthopedic surgery: a double-blind, randomized comparison of racemic bupivacaine and ropivacaine. J Clin Anesth 2003; 15: 126-31.

20. Koch T, Fichtner A, Schwemmer U, Standl T, Volk T, Engelhard K, et al. Levobupivacaine for epidural anaesthesia and postoperative analgesia in hip surgery: a multi-center efficacy and safety equivalence study with bupivacaine and ropivacaine. Anaesthesist 2008; 57: 47582.

21. McGlade DP, Kalpokas MV, Mooney PH, Buckland MR, Vallipuram SK, Hendrata MV, et al. Comparison of 0.5\% ropivacaine and 0.5\% bupivacaine in lumbar epidural anaesthesia for lower limb orthopaedic surgery. Anaesth Intensive Care 1997; 25: 262-6.

22. Yang CW, Jung SM, Kwon HU, Kang PS, Ryu SH. Comparison of Epidural Anesthesia with $0.5 \%$ Levobupivacaine and $0.5 \%$ Ropivacaine for Cesarean Section. Korean J Anesthesiol 2007; 52: 284-90.

23. Taspinar V, Sahin A, Dönmez NF, Pala Y, Selçuk A, Ozcan M, et al. Low dose ropivacaine or levobupivacaine walking spinal anesthesia in ambulatory inguinal herniorrhaphy. J Anesth 2011; 25: 219-24. 